\title{
Role of Vitamin D in Near Sightedness
}

\author{
Yasir Iqbal ${ }^{1}$, Aqsa Malik², Rabbia Shabbir ${ }^{3}$, Atteaya Zaman ${ }^{4}$, Masooma Talib ${ }^{5}$ \\ ${ }^{1,5}$ Watim Medical and Dental College, Rawat, Rawalpindi, ${ }^{2}$ Department of Biochemistry, Medical College, Mirpur, \\ ${ }^{3}$ Department of Biochemistry, HITEC. IMC Dental College, Taxilla, ${ }^{4}$ Federal Medical and Dental College, \\ Islamabad
}

\begin{abstract}
Purpose: To determine the levels of Vitamin D in children with myopia and to compare them with age matched controls.

Study Design: Case control study.

Place and Duration of Study: The study was conducted in Naseer Memorial Hospital, Dadhyal Azad Kashmir from March 2016 to March 2017.

Methods: Two hundred patients were selected using convenient sampling technique and were divided two groups (group I Myopic and group II control). Myopia was labeled if after subjective refraction a Spherical Equivalent (SE) of -0.50 diopters (D) or more was found. Vitamin $D$ levels were measured by radioimmunoassay technique with Diasorin SR® kit following the user's manual. Vitamin D levels less than $20 \mathrm{ng} / \mathrm{ml}$ were considered Vitamin D deficient following the standards of American academy of pediatrics. The collected data was entered in the statistical package for social sciences (SPSS) version 21 for analysis. Independent t-test was used to determine the significant difference of means between controls and patients. P-values less than 0.05 were considered significant.
\end{abstract}

Results: Mean age of controls and myopes were $10.65 \pm 3.9$ and $10.20 \pm 2.5$ years respectively. Vitamin D levels in myopic children were found to be $14.95 \pm 3.75 \mathrm{ng} / \mathrm{ml}$ and there was no significant difference in mean values of Vitamin D levels in myopic and control group.

Conclusion: We found no difference in Vitamin D levels of myopic and non myopic children and concluded that Vitamin $D$ has no role in development or progression of myopia.

Key Words: Vitamin D, Myopia, Refractive error, Objective refraction.

How to Cite this Article: lqbal Y, Malik A, Shabbir R, Zaman A, Talib M. Role of Vitamin D in Near Sightedness, Pak J Ophthalmol. 2020; 36 (2): 136-140.

Doi: $10.36351 /$ pjo.v36i2.990

\section{INTRODUCTION}

Types of refractive errors are myopia, hyperopia and astigmatism. ${ }^{1}$ In Myopia, the person is able to see near objects and the distant ones are blurry hence the term

Correspondence: Yasir Iqbal

Watim Medical and Dental College, Rawat, Rawalpindi

Email:yazeriqbal@gmail.com

Received: January 24, 2020

Accepted: March 8, 2020 near sightedness. It can occur at any age like in childhood or adolescence and even in old age. There is no gender predisposition and is affected globally. ${ }^{2}$ It can be classified as physiologic and pathologic. The cause of physiological myopia can be high curvature of the cornea, nuclear sclerosis and elongated eyeball or combination of these factors with the absence of any other ocular pathology. ${ }^{3}$ The cause of pathologic myopia is abnormal lengthening of the eyeball leading to thinning of the sclera wall and other complications. Another classification is based on age of onset. It tends to run in the families and no occupational association has been found. 
Myopia is prevalent in $20 \%$ of the population worldwide and is estimated that $12 \%$ children are affected. $^{2}$ In Pakistan its prevalence is $6 \%$ in adults and in children it is reported as high as $21 \%{ }^{4,5}$ The figure is on the rise every year and is presenting as major global health problem. ${ }^{2}$ Not only it has a social impact on the individual, making the person unable to perform the tasks of desire, it acts as a factor in adding individuals with less productivity. ${ }^{6}$ Furthermore, myopia is a risk factor for other visually blinding diseases like glaucoma and retinal detachment which further implicates on the health system. For these reasons the pathophysiology of development of myopia remained a hot debate since ages.

The pathophysiology of myopia had been associated with many myths. Reading books in dim light or while lying on bed, watching too much television and even deficiency of Vitamin A had been proclaimed but no scientific reason was found. Some researchers advocate genetic predisposition and have identified numerous genetic loci linked with myopia whereas others have attributed to less outdoor activity and Vitamin D deficiency. ${ }^{7.8}$

Vitamin D, once considered a Vitamin, is now being treated as a hormone. Many studies have demonstrated Vitamin D having effects on biological processes like calcium and phosphorus metabolism regulation as well as cell proliferation and differentiation, immune regulation and neurogenesis. ${ }^{9,10}$ It is found to be associated with cardiovascular diseases, cancers, autoimmune and infectious diseases. About $90 \%$ of the Vitamin D is derived from the skin and around 10\% from diet. There are two forms of Vitamin D, Vitamin D3 (cholecalciferol) and Vitamin D2 (ergocalciferol). Vitamin D3 is derived from the skin after exposure to ultraviolet light. After absorption from intestines and the synthesis by skin, Vitamin D is converted into $25(\mathrm{OH}) \mathrm{D}$ in the liver. If the $25(\mathrm{OH}) \mathrm{D}$ levels are greater than or equal to $30 \mathrm{ng} / \mathrm{ml}$ it is considered as normal and less than this is considered as Vitamin D deficiency. ${ }^{11}$

Recently time spent outdoors has become area of interest in myopia research. Researchers have found low incidence of myopia in those who spent more time outdoors as compared to the ones who are more involved in indoor activities, which led to the concept that Vitamin D might be a possible moderator of this association. ${ }^{8}$ Researchers have reported high incidence of myopia in children aged 5 to 15 years. ${ }^{12}$ Therefore, in this study we compared Vitamin D levels of myopic and non-myopic children in order to determine whether Vitamin D has a role in myopia pathophysiology or not.

\section{METHODS}

It was an observational case-control study conducted at Naseer Memorial Hospital, Dadyal Azad Kashmir, from March 2017 to March 2019. The study was conducted according to the guidelines of Declaration of Helsinki. A formal verbal consent from the children and their parents was taken before the commencement of the study. After fulfilling the inclusion and exclusion criteria, patients were selected using convenient non-probability sampling technique and were divided two groups (group I Myopic and group II control). Selection criteria for group I was; children of any gender with age between 5 to 15 years and diagnosed with physiological myopia. Group II were age-matched controls. Subjects with history of ocular surgery, eye diseases like glaucoma, uveitis, retinal disease, cataract, systemic disease, any therapeutic regimen or steroid use were excluded from the study. Demographic information i.e., age, gender and history of systemic disorders were recorded. Children underwent complete ocular examination including visual acuity, detailed slit lamp examination, intraocular pressure measurement and ophthalmoscopy before cycloplegic retinoscopy was done. Myopia was labeled if after subjective refraction a Spherical Equivalent (SE) of -0.50 diopters (D) or more was found (Mild myopia if SE less than $-3.0 \mathrm{D}$; moderate myopia if greater than or equal to $-3.0 \mathrm{D}$; and high myopia was defined as more than or equal to $-6.0 \mathrm{D}$ ). Children with myopia were included in group I whereas those having astigmatism and hyperopia was excluded. Children with no refractive error were included in the control group.

Informed consent was taken from the parents of all participants. For assessment of Vitamin D levels, 2cc of venous blood was collected and after centrifugation serum was stored at $-20^{\circ} \mathrm{C}$ temperature in laboratory freezer for further analysis. Vitamin D levels were measured by radioimmunoassay technique with Diasorin SR ${ }^{\circ}$ kit following the user's manual. Vitamin D levels less than $20 \mathrm{ng} / \mathrm{ml}$ were considered Vitamin D deficiency following the standards of American academy of pediatrics.

The collected data was entered in the statistical 
package for social sciences (SPSS) version 21 for analysis. Gender was expressed as percentages and frequency whereas numerical variables like age and Vitamin D levels were expressed as mean and standard deviation. Independent $\mathrm{t}$-test was used to determine the significant difference of means between controls and patients. $P$ values less than 0.05 was considered as significant.

\section{RESULTS}

A total of 1587 children in between the age of $5-15$ years were examined during the study period. After fulfilling the inclusion /exclusion criteria, 100 children were selected by simple convenient sampling method for each group. Group I consisted of $47.18 \%$ males and $52.11 \%$ females whereas in group II were $55.82 \%$ males and $44.17 \%$ females. The mean ages of controls and myopics were $10.65 \pm 3.9$ and $10.20 \pm 2.5$ years respectively. The age difference between the two groups was statistically insignificant (Table 1). In group I, $79.4 \%$ had mild myopia, $19.6 \%$ had moderate myopia and $0.6 \%$ had high myopia. The Vitamin D levels in myopic children were found to be $14.95 \pm$ $3.75 \mathrm{ng} / \mathrm{ml}$ and there was no significant difference in mean values of Vitamin D levels in myopic and control group.

Table 1: Descriptive Statistics for the Myopia and Control.

\begin{tabular}{|c|c|c|c|c|}
\hline & & $\begin{array}{c}\text { Group I } \\
\text { (Myopia) } \\
\mathbf{n}=\mathbf{1 0 0}\end{array}$ & $\begin{array}{c}\text { Group II } \\
\text { (Control) } \\
\mathbf{n}=\mathbf{1 0 0}\end{array}$ & P-value \\
\hline \multicolumn{2}{|c|}{$\begin{array}{l}\text { Mean Age } \\
(\text { years } \pm S D)\end{array}$} & $10.20 \pm 2.5$ & $10.65 \pm 3.9$ & 0.789 \\
\hline Gender & $\begin{array}{l}\text { Male } \\
\text { Female }\end{array}$ & $\begin{array}{l}47.18 \% \\
52.11 \%\end{array}$ & $\begin{array}{l}55.82 \% \\
44.17 \%\end{array}$ & $\begin{array}{l}0.675 \\
0.647\end{array}$ \\
\hline \multirow{2}{*}{\multicolumn{2}{|c|}{$\begin{array}{l}\text { Serum Vitamin D } \\
\text { levels (ng/ml) } \\
\text { Spherical equivalent } \\
\text { refractive error (D) }\end{array}$}} & $15.95 \pm 3.75$ & $16.02 \pm 5.11$ & 0.625 \\
\hline & & $-3.08 \pm 2.45$ & $+0.25 \pm 0.26$ & $\begin{array}{l}\text { Not } \\
\text { applicable }\end{array}$ \\
\hline
\end{tabular}

\section{DISCUSSION}

The pathogenesis of myopia has been a hot debate since ages. Its association with excessive near work and less outdoor activity has been advocated by many. ${ }^{13}$ Atta $\mathrm{Z}$ et al found myopia in $52.6 \%$ of the children studying in madrasas and proposed less outdoor activity to be associated with myopia. ${ }^{14}$ Similarly, Pan CW found that children involved more in outdoor activity have less chances of myopia. ${ }^{15}$ Similar idea was advocated by Tideman JW et al. ${ }^{16}$
But the question remained unanswered that how outdoor activity affects refractive error development. It was proposed that better quality of retinal image is attained while viewing distant objects with a small pupil size and accommodative errors may be inhibiting ocular growth and decreasing the risk of myopia. ${ }^{17}$ However, evidence from animal models did not support this hypothesis. Another proposed hypothesis was an increase in retinal dopamine secretion in response to bright light during outdoors suppresses axial elongation but again no scientific evidence was presented.

Vitamin D is a vital element for absorption of calcium in the intestines and plays a significant role in the growth of bones along with mineral and Calcium homeostasis. ${ }^{9}$ The commonly used indicator of Vitamin D status is serum $25(\mathrm{OH})$ D concentrations. Researchers have found a strong association between serum $25(\mathrm{OH})$ D concentrations and myopia advocating greater time spent outdoors reduces the risk of myopia. Sherwin JC et al reported low serum concentrations of Vitamin D in myopes. ${ }^{8}$ Similarly, low Vitamin D concentration was reported by Tideman JW et al in patients with high axial length. ${ }^{16}$ How Vitamin D prevents myopia remains to be answered. One theory is that, as deficiency of Vitamin $\mathrm{D}$ leads to alteration of intracellular $\mathrm{Ca}$ level and subsequently causes impaired contraction and relaxation of the ciliary muscles thus leading to myopia. ${ }^{18}$ Another theory is Calcium deficiency secondary to lack of adequate Vitamin D levels leading to head and orbit deformity and consequently myopia of prematurity but against this was the finding of no change in refractive status of low birth weight infants after extra-enteral $\mathrm{Ca}$ supplementation. ${ }^{18}$ Vitamin D is also thought to affect pathological scleral growth and myopia via retinoic acid. Retinoic acid and Vitamin D receptors form heterodimers which participate in signaling and cell-cycle regulation but data based studies are lacking. ${ }^{17}$

In our study, we found no difference in Vitamin D levels of myopics and age matched control. Same finding was reported by another researcher, according to whom myopes prefer to stay indoors and consequently have low $25(\mathrm{OH})$ D3 levels therefore serum $25(\mathrm{OH})$ D3 is simply a biomarker of sun exposure. ${ }^{19}$ Hence outdoor activity might be mediating myopia prevention via some other pathway instead of Vitamin D. Analysis done by Williams KM et al also negated the hypothesis that outdoor activity protects 
against myopia by Vitamin D levels. ${ }^{20}$ Furthermore, he objected that if outdoor activity is protective against myopia it should slow the progression in those who already have myopia. These questions are yet to be answered.

In our study the participants had below normal mean $25[\mathrm{OH}] \mathrm{D}$ concentrations and were below the accepted normal value of $20 \mathrm{ng} / \mathrm{ml}$. This is in contrast to other studies in which only myopes had low levels of Vitamin D. ${ }^{15,16}$ This might be due to other factors like ethnicity, outdoor activity and diet. Vitamin D deficiency is reported more in African Americans compared to Caucasians and more in the regions of Middle East, China, Mongolia, and the Indian subcontinent. ${ }^{21}$ The confounder of ethnicity was not addressed in our study. Likewise, high Vitamin D levels and less incidence of myopia is advocated to be associated with more outdoor activity and to higher dietary intake of Vitamin D. ${ }^{16}$ Mutti et al found no association. ${ }^{17}$ According to Mutti et al the prevalence of myopia is on the rise in Asian population despite the Vitamin D rich fish diet. Therefore, further researchis needed to identify relevant biological connections between Vitamin D and myopia. The diet confounder was also not taken into account in our study.

Limitation of the study is that it was an observational study not a randomized trial. The confounding factors like time spent outdoors, seasonal variation of measurement and sunlight exposure, dietary habits and demographic variables were not taken into account.

\section{CONCLUSION}

We found no difference in Vitamin D levels of myopic and non myopic children and concluded that Vitamin $\mathrm{D}$ has no role in development or progression of myopia.

\section{Ethical Approval}

The study was approved by the Institutional review board/Ethical review board.

\section{Conflict of Interest}

Authors declared no conflict of interest

\section{REFERENCES}

1. Iqbal Y, Niazi FK, Niazi MA. Frequency of Eye Diseases in School Age Children. Pak J Ophthalmol. 2009; 25 (4):147-150

2. Morgan I, He M, Saw S, Krueger R, Lam D. Myopia. Asia Pac J Ophthalmol. 2016; 5 (6): 383-385.

3. Kumar A, Chawla R, Kumawat D, Pillay G. Insight into high myopia and the macula. Indian J Ophthalmol. 2017; 65 (2): 85-91.

4. Abdullah AS, Jadoon MZ, Akram M, Awan ZH, Azam M, Safdar M, et al. Prevalence of uncorrected refractive errors in adults aged 30 years and above in a rural population in Pakistan. J Ayub Med Coll. 2015; 27 (1): 8-12.

5. Latif MZ, Khan MA, Afzal S, Gillani SA, Chouhadry MA. Prevalence of refractive errors; evidence from the public high schools of Lahore, Pakistan. J Pak Med Assoc. 2019; 69 (4): 464-467.

6. Guo W, Woodward MA, Heisler M, Blachley T, Corneail L, Cederna J, et al. Risk factors for visual impairment in an uninsured population and the impact of the Affordable Care Act. Clinics in Surgery, 2016; 134: 802-809.

7. Li M, Zhai L, Zeng S, Peng Q, Wang J, Deng Y, et al. Lack of association between LUM rs3759223 polymorphism and high myopia. Opt Vis Sci. 2014; 91 (7): 707-712.

8. Sherwin JC, Hewitt AW, Coroneo MT, Kearns LS, Griffiths LR, Mackey DA. The association between times spent outdoors and myopia using a novel biomarker of outdoor light exposure. Invest Ophthalmol Vis Sci. 2012; 53 (8): 4363-4370.

9. Bhatt N, Ali A, Waly MI. Non-Skeletal Benefits of Vitamin D. Canad J Clin Nutr. 2019; 7 (1): 141-159.

10. Meehan M, Penckofer S. Role of Vitamin D in aging adult. J Aging Gerontol. 2014; 2 (2): 60-71.

11. Tangpricha V, Koutkia P, Rieke SM, Chen TC, Perez AA, Holick MF. Fortification of orange juice with vitamin $\mathrm{D}$ : a novel approach for enhancing vitamin D nutritional health. Am J Clin Nutr. 2003; 77 (6): 1478-1483.

12. Wu PC, Huang HM, Yu HJ, Fang PC, Chen CT. Epidemiology of myopia. The Asia Pac J Ophthalmol. 2016; 5 (6): 386-393.

13. Polling JR, Verhoeven VJ, Tideman JW, Klaver CC. Duke-Elder's views on prognosis, prophylaxis, and treatment of myopia: way ahead of his time. Strabismus, 2016; 24 (1): 40-43.

14. Atta Z, Arif AS, Ahmed I, Farooq U. Prevalence of refractive errors in Madrassa students of Haripur district. J Ayub Med Coll. 2015; 27 (4): 850-852.

15. Pan CW, Qian DJ, Saw SM. Time outdoors, blood Vitamin D status and myopia: a review. Photoch Photobio Sci. 2017; 16 (3): 426-432. 
16. Tideman JW, Polling JR, Voortman T, Jaddoe VW, Uitterlinden AG, Hofman A, et al. Low serum Vitamin D is associated with axial length and risk of myopia in young children. Eur J Epidemiol. 2016; 31 (5): 491-499.

17. Mutti DO, Marks AR. Blood levels of Vitamin D in teens and young adults with myopia. Opto Vis Sci. 2011; 88 (3): 377.

18. Carroll WF, Fabres J, Nagy TR, Frazier M, Roane C, Pohlandt F, et al. Results of extremely low birth weight infants randomized to receive extra enteral calcium supply. J Pediat Gastroenterol Nutr. 2011; 53 (3): 339.

19. Guggenheim JA, Williams C, Northstone K, Howe LD, Tilling K, St Pourcain B, et al. Does Vitamin D mediate the protective effects of time outdoors on myopia? Findings from a prospective birth cohort. Invest Ophthalmol Vis. Sci. 2014; 55 (12): 8550-8558.

20. Williams KM, Bentham GC, Young IS, McGinty A, McKay GJ, Hogg R, et al. Association between myopia, ultraviolet $\mathrm{B}$ radiation exposure, serum Vitamin D concentrations, and genetic polymorphisms in Vitamin D metabolic pathways in a multicountry European study. JAMA Ophthalmology, 2017; 135 (1): 47-53.
21. Van Schoor NM, Lips P. Worldwide Vitamin D status. Best Pract Res Clin Endocrinol Metab. 2011; 25 (4): 671-680.

\section{Authors' Designation and Contribution}

Yasir Iqbal; Associate Professor: Study design, Data Collection, Manuscript Writing, Final review.

Aqsa Malik; Assistant Professor: Study design, Manuscript Writing, Final review.

Rabbia Shabbier; Lecturer: Study design, Final review.

Atteaya Zaman, Assistant Professor: Study design, Final review.

Masooma Talib; Assistant Professor: Study design, Final review. 